\title{
Laboreal
}

Volume 11 N² | 2015

Varia

\section{A aliança Teoria / Prática na obra do sociólogo do trabalho Georges Friedmann (1922-1977)}

\section{Catherine Teiger}

\section{(2) OpenEdition}

\section{Journals}

\section{Edição electrónica}

URL: http://journals.openedition.org/laboreal/3800

DOI: 10.4000/laboreal.3800

ISSN: 1646-5237

\section{Editora}

Universidade do Porto

\section{Refêrencia eletrónica}

Catherine Teiger, «A aliança Teoria / Prática na obra do sociólogo do trabalho Georges Friedmann (1922-1977) », Laboreal [Online], Volume 11 №2 | 2015, posto online no dia 01 dezembro 2015, consultado o 24 setembro 2020. URL : http://journals.openedition.org/laboreal/3800 ; DOI : https:// doi.org/10.4000/laboreal.3800

\section{Este documento foi criado de forma automática no dia 24 setembro 2020.}

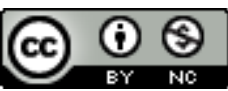

Laboreal está licenciado com uma Licença Creative Commons - Atribuição-NãoComercial 4.0 Internacional. 


\title{
A aliança Teoria / Prática na obra do sociólogo do trabalho Georges Friedmann (1922-1977)
}

\author{
Catherine Teiger
}

\section{REFERÊNCIA}

Comentário ao texto: Friedmann, G. (1954). Intervention au XIème Congrès International de Psychotechnique (Psychologie appliquée), Section de psychologie du travail, Paris, 1953. Le Travail Humain, 17, 1-2, 39-40.

\section{NOTA DO EDITOR}

http://dx.doi.org/10.15667/laborealxi0215ctpt

Para que o tamanho deste comentário não exceda (demasiado!) o do texto de Georges Friedmann (1902-1977) proposto neste número da Laboreal, irei apenas situá-lo no seu contexto histórico pessoal, académico e societal, e levantar uma das questões de fundo que ele colocou aos seus contemporâneos. Uma questão epistemológica que se coloca ainda hoje, apesar de os contextos terem mudado bastante. Ao fazê-lo, enquadro-me na reflexão do sociólogo belga Mateo Alaluf (2001, p.102, tradução livre): "O regresso aos debates que se possam julgar antigos continua a ser o melhor antídoto para nos salvar da amnésia que nos ameaça incessantemente nas ciências sociais e que fragiliza tanto os nossos resultados". É por esta razão que os debates que marcaram o pós-guerra esse período de grandes transformações, que é também o da emergência da ergonomia e de uma nova sociologia do trabalho nos anos cinquenta - permanecem tão atuais.

O texto - sem outro título que não o aqui indicado - foi retirado de Actes du XIe Congrès international de Psychotechnique (Psychologie appliquée) - Section de psychologie du Travail (Actas do XI ${ }^{\circ}$ Congresso internacional de Psicotécnica (Psicologia aplicada ${ }^{1}$ ) - Secção de 
psicologia do Trabalho) que teve lugar em Paris em 1953. Trata-se da retranscrição da reação do "filósofo - psicólogo - sociólogo", Professor Georges Friedmann, às apresentações da sessão plenária inaugural. A sua intervenção seguiu-se às dos ingleses C. B. Frisby (1954) 2 ("Allocution inaugurale"-"Discurso Inaugural") e L. S. Hearnshaw (1954)3("Le but et le domaine de la psychologie industrielle" - "O propósito e o âmbito da psicologia industrial”), do francês Pierre Goguelin(1954) ("Les facteurs psychologiques susceptibles d'accroitre la productivité en entreprise" - "Os fatores psicológicos suscetíveis de aumentar a produtividade na empresa") e do Sueco Gunnar Westerlund (1954) ("Cadre de références et problèmes liés en psychologie industrielle" -"Quadro de referências e problemas relacionados em Psicologia Industrial"). Todavia, a reacção de Georges Friedmann visa sobretudo a intervenção de L. S. Hearnshaw, ou seja, a definição do âmbito da psicologia do trabalho.

A este propósito, Georges Friedmann (G.F.) evoca, entre outros aspetos, as relações entre teoria e prática, apoiando-se numa posição já antiga (1932) de Jean-Maurice Lahy ${ }^{6}$ (1872-1943), sobre a qual me pronunciarei a seguir. Notemos que G.F. não faz nenhuma referência direta a P. Goguelin, mas, ao citar a psicóloga Suzanne Pacaud, colaboradora durante inúmeros anos de J.-M. Lahy, não deixou de mencionar os riscos de falhanço de uma "política da produtividade" que não tiver em conta as inter-relações entre todas as dimensões do trabalho e que deste modo não mereceria "a colaboração de psicólogos industriais preocupados em não comprometer a sua atividade ao serviço dos interesses particulares e de a manter num terreno científico". Na verdade, a política de produtividade estava no seu auge no período pós-guerra, sob o impulso do plano Marshall de ajuda dos EUA à reconstrução e à modernização dos países da Europa devastados pela guerra e sob a influência das "missões de produtividade" que, então, visitaram os EUA. Estas envolveram toda a comunidade profissional ${ }^{7}$ (Kuisel, 1988), apesar da oposição dos círculos profissionais comunistas, que denunciaram um "projeto de catequização da classe operária" (Brucy, 2001, p. 81, tradução livre). Recordemos que uma destas missões, em 1956 - "O projeto 335" ou "Adaptation du travail à l'homme" ("Adaptação do trabalho ao homem") - contribuiu para a emergência da ergonomia na Europa (AEP, 1959; Teiger \& Lacomblez, 2013). Encontramos também referências a uma "Missão psicotécnica" de 1952 (com psicólogos, incluindo S. Pacaud e Jean-Marie Faverge), nomeadamente, nos capítulos redigidos por J. M. Faverge (Teiger, 2015a) na obra "L'analyse du travail. Facteur d'économie humaine et de productivité" ("A análise do trabalho. Fator de economia humana e de produtividade") (Ombredane \& Faverge, 1955).

\section{Mas quem foi Georges Friedmann (1902-1977)? Alguns flashes biobibliográficos ${ }^{8}$.}

Todos estão de acordo em caracterizar G.F. como uma das figuras de proa emblemáticas dos intelectuais progressistas da pós-segunda guerra mundial (1939-45), seduzidos pelo ideal comunista de justiça social e muitos deles "compagnons de route" do Partido Comunista Francês (PCF), tendo posteriormente, no final dos anos 50, abandonado e entrado em rutura definitiva. Pioneiro de uma "sociologia humanista", contribuiu de forma decisiva para a nova sociologia francesa e, sobretudo, para a promoção da sociologia do trabalho. Ele permaneceu engajado durante a sua vida, que consagrou à 
análise do trabalho humano, e em função da evolução do mundo técnico ele próprio evoluiu através das suas análises.

Nascido em 1902, ingressou em 1923 na École Normale Supérieure em Paris (ENS) onde concluiu a agregação em filosofia. Depois, graças aos financiamentos concedidos à ENS pela Fundação Rockefeller (Tournès, 2008), ele exercerá, durante três anos, de 1932 a 1935, o cargo de assistente do "Centro de documentação social" alojado na ENS", enquanto assistente para os estudantes da Escola. Para compreender melhor o trabalho operário, ele seguiu, a meio-tempo, entre 1931 e 1932, uma aprendizagem de afinador de máquinas na escola profissional Denis Diderot, em Paris, mas nunca chegou a trabalhar como operário numa fábrica.

Fez três viagens à URSS (em 1932, 1933 e 1936) e apoiar-se-á nas suas observações (Friedmann, 1934) para realizar uma reflexão sobre o maquinismo no âmbito da sua tese publicada em 1946: "Problèmes humains du machinisme industriel" ("Problemas humanos do maquinismo industrial") que introduziu, em França, a nova sociologia do trabalho. Viajou também para os EUA.

Leccionou depois, de 1935 a 1939, na escola profissional Boulle, de onde foi expulso, ao abrigo das leis anti-semitas do governo de Vichy vigente durante a ocupação da França pela Alemanha nazi. Tendo entrado na Resistência na região de Toulouse, viveu na clandestinidade. Não obstante, a 23 de junho de 1941 realizou-se a "Journée interdisciplinaire de psychologie et d'histoire du travail et des techniques" ("Jornada interdisciplinar de psicologia e de história do trabalho"), organizada por iniciativa do psicólogo Ignace Meyerson (1888-1983) para a "Société d'études psychologiques de Toulouse" ("Sociedade de estudos psicológicos de Toulouse"), criada, aliás, em maio de 1941. As Actas deste encontro - "Le travail et la technique" ("O trabalho e a técnica") - só foram publicadas em 1948, tendo sido objeto de uma recensão elogiosa por parte da revista "Annales" em 1951, e, em particular, pelo historiador Lucien Febvre, ele mesmo um participante da Jornada ${ }^{10}$. Entre as intervenções analisadas figura a de G. F. ("Esquisse d'une psycho-sociologie du travail à la chaîne"- "Esboço de uma psicossociologia do trabalho em cadeia") que L. Febvre apresenta como "o nosso amigo". Ora, nesta comunicação, G. F. formula uma primeira teorização de "Problèmes humains du machinisme industriel" ("Problemas humanos do maquinismo industrial") (Friedmann, 1946), tema da sua tese, publicada em 1946, onde ele defende que o trabalho em cadeia representa "uma etapa histórica do desenvolvimento da sociedade industrial" e que "os problemas do trabalho humano são simultaneamente problemas técnicos, problemas psicológicos e problemas sociais" (Friedmann, 1941/48, p.127, tradução livre). E L. Febvre termina a sua recensão desta forma: "Vemos o interesse deste número (da revista "Annales"), muito bem-sucedido. Este encontro presta homenagem àqueles que o projetaram e este número permanecerá útil e vivo durante muito tempo" (1951, p. 243, tradução livre).

Após o fim da guerra, G.F. é nomeado inspetor geral do ensino técnico (em 1945), professor de história do trabalho no Conservatoire national des arts et métiers (CNAM, de 1946 a 1960), diretor de estudos na École pratique des hautes études (EPHE, de 1949 a 1960) e diretor do Centre d'études sociologiques (CES) do Centre National de la Recherche Scientifique (CNRS de 1949 a 1954). Funda em 1959, com outros, a revista Sociologie du travail. Por fim, no início dos anos 1960, explora um outro campo da cultura técnica: as comunicações e a cultura de massa. 
Em 1962, G.F. coordenará com Pierre Naville o importante Traité de sociologie du travail ${ }^{11}$ ("Tratado de sociologia do trabalho") (Friedmann \& Naville, 1962) a seguir à publicação em 1958 do Traité de sociologie ("Tratado de sociologia") coordenado por Georges Gurvitch, para o qual ele havia escrito com Jean-Daniel Reynaud "Sociologie des techniques de production et du travail" ("Sociologia das técnicas de produção e do trabalho").

Em 1953-54, época que corresponde à sua intervenção no congresso que aqui nos ocupa, G.F. é então, como já foi dito, professor de história do trabalho no CNAM e diretor de estudos na ÉPHE, acumulação de funções frequente na época. Ele é, então, uma autoridade no domínio das ciências do trabalho. Reorientou as atividades do CES que até aí organizava sobretudo conferências. Com ele, o CES tornou-se um laboratório de inquéritos. Uma nova "fórmula de pesquisa" foi adoptada, com entrevistas ${ }^{12} \mathrm{e}$ observações (como nos EUA), embora a prática de inquéritos coletivos existisse em França já desde os anos trinta, altura da emergência de uma política de promoção das ciências sociais ${ }^{13}$ (Tournès, 2008).

O contexto dos anos cinquenta facilitou a evolução da sociologia acima mencionada graças às oportunidades proporcionadas pela criação, em 1951 - por iniciativa do Ministério do trabalho com vista à formação dos conselheiros do trabalho - do Institut des sciences sociales du travail (ISST) ligado à Universidade de Paris. A secção de investigação foi criada em 1954 com Yves Delamotte ${ }^{14}$, secretário-geral do novo Instituto no qual G.F. se tornou diretor. O jurista Marcel David ${ }^{15}$ sucedeu-lhe em 1959. Este último criou, graças à sua vontade de ferro, nos mesmos anos (em 1955), o primeiro Instituto do trabalho na Faculdade de direito da Universidade de Estrasburgo, tendo em vista a formação superior dos sindicalistas chamados a participar e negociar nas instâncias paritárias que tinham sido recentemente criadas (David, 1982).

Para sustentar tais formações superiores, cuja finalidade é concreta e não académica, serão indispensáveis inquéritos empíricos atualizados. Tal necessidade reforçou uma tendência emergente no contexto do pós-guerra. Com efeito, G. F. tinha já lançado, a partir de 1949, através do CES, grandes inquéritos na indústria: os de Alain Touraine e Etienne Verey nas fábricas Renault (Touraine, 1955), de Viviane Isambert-Jamati na indústria relojoeira (1955) e de Maurice Verry na siderurgia das Ardennes (1955). Tais realizações serão facilitadas pelas significativas dotações financeiras disponibilizadas pelo plano Marshall, a partir de 1954 ao ISST e a outras instituições ${ }^{16}$. Assim, as investigações iniciadas em seguida por G.F. sobre "as atitudes dos operários da siderurgia face às mudanças técnicas" enquadrar-se-ão efetivamente em projetos apoiados pelo plano Marshall (no quadro da Organização Europeia de Cooperação Econômica/OECE), sendo conduzidos conjuntamente na Alemanha, Bélgica, França, Grã-Bretanha e Itália.

Em relação à França, tratar-se-á da pesquisa sobre os operários da siderurgia, realizada em Mont-Saint-Martin (1954-1957) por J.D. Reynaud, A. Touraine e seus colaboradores, e também da investigação sobre os funcionários subalternos dos "Chèques postaux" de Paris (Crozier, 1956). A pesquisa na siderurgia de Mont-Saint-Martin foi realizada por jovens investigadores ${ }^{1718}$ que se autodesignaram os "Gaston". G. Rot e F. Vatin (2008) publicaram e analisaram mais tarde o diário mantido pelos Gaston. Enriquecido com desenhos humorísticos, tal diário reflete bem as perplexidades, as descobertas, as dificuldades das suas tarefas, assim como as reações destes investigadores aprendizes 
perante a divisão do trabalho intelectual que vivem - eles no terreno dia e noite e os "chefes" no escritório em Paris à espera dos relatórios!

E, de facto, isto levanta a questão de fundo colocada neste texto por G.F.: a da relação entre teoria / prática, ciências fundamentais / ciências aplicadas.

\section{Teoria / prática; laboratório / terreno. Porquê, onde e como fazer ciência e que ciência?}

A questão central do pensamento de G.F., que realçarei no âmbito deste comentário, é a da relação entre teoria e prática (ou teoria e empirismo) que, atualmente, ainda afecta a maior parte das disciplinas das ciências humanas e sociais que se interessam pelo trabalho humano, tais como a ergonomia, a psicologia, a sociologia e a filosofia. Encontramos também um questionamento semelhante nos epistemólogos-historiadores de ciências como a etologia (Despret, 2011).

\section{Teoria e prática: de que se trata?}

É conhecido o aforismo humorístico atribuído ao físico Albert Einstein, pai da teoria da relatividade: "A teoria é quando se sabe tudo e nada funciona. A prática é quando tudo funciona e ninguém sabe porquê. Aqui, reunimos teoria e prática: nada funciona e ninguém sabe porquê!"

A intervenção no XI ${ }^{\circ}$ Congresso internacional de psicotécnica, em 1953, será a oportunidade para G.F., titular durante 7 anos da cadeira de "História do trabalho e relações industriais" do CNAM, fundamentar o seu ponto de vista sobre a abordagem do trabalho. Em ligação com o desenvolvimento da tomada em consideração do fator humano, G.F. destaca os limites de uma conceção que separa teoria e prática. E recorda a posição de J.-M. Lahy (1932) que defendia que a psicologia aplicada, ou psicotécnica, não é outra coisa que psicologia científica geral, sustentando assim que ela não difere da psicologia teórica mas que, nascida dela, ela supera-a, transforma-a e substitui-a como produto da sua evolução necessária, como uma síntese da teoria com uma nova prática. Sendo assim, talvez se pudesse conseguir que tudo funcione e que se saiba porquê! No mesmo espírito, 70 anos depois, o antropólogo Maurice Godelier ${ }^{19}$ (2000, p. 15, tradução livre), afirmará: "As pesquisas em ciências sociais pertencem desde o início à esfera da investigação fundamental (...) São como as ciências duras, ciências fundamentais que podem ter aplicações. Porque não existe realmente investigação aplicada mas existem, sim, aplicações da investigação".

Este tema abrange pelo menos cinco aspetos que estão relacionados: 1) os locais e os métodos privilegiados de produção de conhecimento; 2) o valor dos conhecimentos produzidos, em função do local da sua produção; 3) a sua utilidade social; 4) a sua formalização e sua difusão; 5) a evolução das teorias. Menciono aqui só os aspetos que ainda estão na agenda da ergonomia. E que são regularmente objeto de jornadas de estudos onde as questões advindas da prática colocam questões teóricas que interrogam as disciplinas e contribuem para o seu desenvolvimento (cf. por exemplo, Les Journées annuelles de l'université de Bordeaux sobre a prática da ergonomia e, também, o Seminário transversal do Institut National d'Etudes sur le Travail et l'Orientation Professionnelle - Groupe de Recherches sur l'Histoire du Travail et de 
l'Orientation em Paris, em 2013, sobre as relações terreno / laboratório, sobre a intervenção, etc.).

\section{(1) Os locais e métodos de produção de conhecimentos: duas aceções das relações teoria / empirismo, terreno / laboratório}

Se a legitimidade das pesquisas de terreno atualmente está já adquirida, todavia ainda existem muitas questões por resolver. Ir para o terreno, mas para fazer o quê?

Ao examinar os argumentos avançados para legitimar a importancia atribuída aos dados empíricos no processo intelectual de produção de conhecimentos sobre o trabalho em particular (Teiger, 2015b), constata-se que a defesa de uma abordagem no terreno reenvia-nos para dois argumentários diferentes. De um lado, a ideia de um terreno subordinado à teoria: como uma extensão do laboratório, onde se confirmam ou se infirmam as hipóteses que a teoria havia estabelecido a priori, aportando um valor adicional de "validade ecológica", sem considerar os problemas próprios dos atores do terreno. Do outro lado, a ideia de um terreno abordado com uma grande abertura às propostas e à atividade real dos atores, bem como aos temas que eles espontaneamente trazem, sem o enquadramento de teorias estruturadas a priori mas com o desejo de contribuir para a resolução das questões que se colocam no terreno.

Se permanecermos no campo da sociologia, e tivermos em conta a oposição entre estas duas compreensões do terreno, apreenderemos melhor o carácter inovador dos sociólogos Friedmannianos. Com efeito, em França, até 1954, momento das primeiras grandes pesquisas de terreno pedidas pelo Estado, a posição dominante no campo dos métodos era ainda a da "sociologia filosófica ${ }^{20}$ / teórica". Mas, a partir desse mesmo momento, os Friedmannianos inventam realmente a nova "sociologia empírica" com, de acordo com M. Alaluf (2012, p.727, tradução livre) "a preocupação metodológica (que) ocupará um lugar central, como garantia de objetividade, no desenvolvimento desta nova sociologia". Mas segundo Olgierd Kuty (2008, p.58, tradução livre).), "este empirismo foi denegrido. A sociologia enfrenta a indiferença, se não a hostilidade". Citando Johan Heilbron (1991, p.366-377, tradução livre), O. Kuty conclui assim: "Entre os polos opostos do "engajamento" e da "perícia" (...), era-lhes extremamente difícil encontrar o seu caminho. 0 sociólogo era colocado numa espécie de "no man's land" e, então, ou ficava paralisado pela angústia de ser demasiado político (e, portanto, não suficientemente intelectual), ou angustiado por não ser suficientemente político, isto é por não estar ao serviço da sociedade".

Encontraremos problemáticas semelhantes a estas, por exemplo, aquando do abandano do laboratório pelos ergónomos, uma dezena de anos mais tarde, na década de sessenta, com vista a melhor compreender o trabalho e contribuir para o transformar tendo em conta a "demanda social" da época (isto é, os efeitos pouco visíveis do trabalho em cadeia sobre a saúde das operárias e operários na produção em massa e nos transportes públicos). Alain Wisner (1985) destaca neste processo um triplo efeito: a necessidade de inventar novos métodos para estudar as situações de terreno no âmbito duma abordagem científica deliberadamente associada à ação; a evolução conceitual que daí deriva e transformará a definição e o próprio objetivo da disciplina ergonomia; finalmente, e também aqui, o desprezo, se não a hostilidade, dos defensores do método experimental em nome da dita neutralidade da ciência (Teiger, 2007, 2015b).

Em ergonomia e psicologia do trabalho, como exemplos dessa abordagem, refira-se o aparecimento e posteiror desenvolvimento das investigações/intervenções ditas 
participativas em França, no fim dos anos sessenta ${ }^{21}$, e em Itália, nos anos setenta, a formalização da "comunidade alargada de pesquisa" pela equipa de Ivar Oddone e sua posteridade intelectual (Oddone et al., 1977; Muniz, et al., 2013; Lacomblez et al., 2014).

\section{(2) 0 valor dos conhecimentos}

Aqui encontramos a questão epistemológica do valor hierarquizado dos conhecimentos, em função do local e dos métodos da sua produção, que a epistemóloga-etóloga belga, Vinciane Despret (2011), coloca com humor no centro da sua reflexão. A autora mostra como, em certos casos, os conhecimentos "práticos" adquiridos pelos tratadores ou treinadores de animais, que são cordialmente menosprezados pelos investigadores da área, permitem no entanto obter resultados que as experiências "científicas" de laboratório muito elaboradas não conseguem ${ }^{22}$ : por exemplo, aprender um mainá desobediente a falar!

Mas ir para o terreno não é suficiente! A quem, de que servirão os resultados da investigação?

\section{(3) A utilidade e a responsabilidade: "a iluminação e a dívida"}

Chegamos, assim, à questão ética da utilidade das pesquisas e dos conhecimentos produzidos e dos seus destinatários; bem como à da responsabilidade dos investigadores-intervenientes na sua relação com os locais de trabalho e com aqueles que aí vivem.

Quem beneficiará dos conhecimentos produzidos ${ }^{23}$ ? A carreira dos investigadores ou as empresas? E que atores das empresas? Ou também as instituições? Vimos já que os Friedmannianos beneficiaram a partir de meados dos anos cinquenta de um certo reconhecimento, pelo menos da parte dos poderes públicos que consideraram os seus trabalhos úteis e os financiaram.

"A iluminação e a dívida", expressão do sociólogo Michel Crozier (1922-2013), teórico do ator no sistema, resume bem os dois lados da relação com o terreno e com os atores do terreno com quem os investigadores-intervenientes trabalham (Kuty, 2008). Por um lado, iluminação pelo sentimento de melhor compreensão da realidade do trabalho e, por outro, dívida que inclui a responsabilidade perante aqueles que trabalham, e com quem se trabalhou, e a quem se deve "entregar" pelo menos alguma parte dos benefícios da compreensão adquirida graças a eles. Segundo M. Alaluf (2012, p.729, tradução livre), na tradição de Friedmann "os investigadores querem-se profissionais de uma ciência útil em oposição à sociologia geral". A teoria sociológica não é um fim em si mesma. Ela deve ser útil, produzir um conhecimento prático, um conhecimento que possa ser um instrumento de mudança, que permita aos interessados melhor compreender a situação em que se encontram e, portanto, serem mais capazes de a mudar. Perante isso, os ergónomos não podem senão concordar!

Voltamos assim à questão dos destinatários da utilidade das investigações, questão sobre a qual haverá sempre divergências profundas, até com posições extremas. Por seu lado, M. Godelier (2000, p. 15, tradução livre) sublinha a utilidade social das ciências sociais: "Os que se envolvem (...) fazem-no crendo que as suas pesquisas vão ser úteis para os outros para além deles mesmos". E continua: "O que abrange este desejo de ser útil? A questão é complexa e as 'utilidades' são bastante diferentes consoante as disciplinas". Contudo, alguns 
autores recusam qualquer noção de utilidade. Gabrielle Varro e Anne-Sophie Perriaux sublinham as posições tomadas pelos sociólogos C. Durand e A. Touraine, nos anos setenta, notando que (1991, p.11, tradução livre): "No importante, mas pouco divulgado, relatório de Durand e Touraine (1970) afirma-se que não é o papel da investigação fazer propostas ou recomendações de ordem administrativa; o seu objetivo é teórico e científico".

Ora, a questão coloca-se de forma um pouco diferente para a ergonomia em França que, após a sua fase "experimental", até meados dos anos sessenta, assumirá claramente o seu duplo objetivo de conhecimento e de ação sobre a situação de trabalho.

\section{(4) Consequência ético-metodológica: formalização e divulgação dos conhecimentos}

Nós defendemos, há bastante tempo, nos domínios da ergonomia e da psicologia do trabalho, uma fórmula de investigação-intervenção que realça a co-elaboração da investigação com os atores envolvidos no terreno, estruturada através de uma formação recíproca à análise do trabalho a partir dos conhecimentos e dos pontos de vista de cada um. Assim, cada um enriquece o seu campo e torna possível uma ação comum. No entanto, uma condição parece-nos ser indispensável para a ação comum nos diferentes domínios: a formalização e a divulgação de uma forma acessível dos conhecimentos e dos diversos instrumentos de análise produzidos durante as investigações/intervenções (Teiger \& Lacomblez, 2013: cf. os dossiers sindicais no DVD anexo). Do nosso ponto de vista, esta reflexão faz parte e deve presidir a todas as operações no terreno a fim de facilitar a apropriação do acervo pelos interessados. Uma das fórmulas interessantes é a de escrever em conjunto (investigadores-intervenientes e atores do terreno em questão) um documento acessível a todos que poderá depois servir de objeto de debate e de instrumento de trabalho (Teiger \& Leal Ferreira, 2015). Contudo, a elaboração e posterior publicação de um tal documento, necessariamente muito demoradas, não têm qualquer valor académico nem profissional; a sua realização está, portanto, dependente da disponibilidade e da boa vontade dos autores-atores. Merece outro apoio e outro reconhecimento.

\section{(5) Uma evolução teórica alimentada pelos conhecimentos vindos da prática do terreno}

Um último efeito importante do contacto de G.F. com o terreno traduziu-se na evolução da sua teorização sobre o trabalho em cadeia, o seu tema de investigação. Forma emblemática da racionalização do trabalho e etapa histórica do desenvolvimento da sociedade industrial, este trabalho em cadeia representa inicialmente para G.F. um "mal necessário", enquanto não se realizarem os esperados benefícios da automatização que será sempre libertadora. Ora este ponto de vista, que é o aspeto mais conhecido do pensamento de G.F., vai evoluir (Rot \& Vatin, 2004) em função dos resultados empíricos dos estudos e investigações levados a cabo em diferentes terrenos pelos seus colegas e discípulos, e, também, em função das suas experiências diretas em situações industriais em diferentes contextos nacionais contrastantes (França, URSS, EUA).

Lendo os primeiros textos de G.F., e em particular a sua comunicação de 1941, só publicada em 1948, somos confrontados com uma ambivalência: admiração, até 
fascínio, pela proeza técnica que representa o trabalho em cadeia, símbolo mesmo do maquinismo e da racionalização do trabalho industrial; mas, ao mesmo tempo, deceção e rejeição de uma forma nefasta de exploração da pessoa humana perante a qual ele não pode ficar insensível. No inicio, G.F. toma uma posição contra "o concerto de maldições e lamentos" que tende a explicar a crise do mundo moderno pelo reinado desumanizante da máquina, tentando demostrar que o drama social evidenciado pela "grande crise" não se deve à técnica mas sim ao capitalismo. Posteriormente, ele adoptará novos argumentos técnicos, em particular após os trabalhos de A. Touraine ${ }^{24}$, e reconfigurará a sua análise, enriquecendo-a com os seus "inquéritos" realizados na Rússia, nos EUA e em França (Alaluf, 2012). Em seguida, no seu importante artigo, "La grande aventure" (“A grande aventura”), editado em 1962, G.F. confirmará essa reorientação teórica e relegará o radicalismo dos seus primeiros trabalhos. Passa, então, a defender a tese da convergência dos sistemas capitalista e socialista, expressões gémeas da mesma "civilização técnica", enquanto antes a sua análise pretendia distinguir o "bom" maquinismo (socialista) do "mau" (capitalista). Que importa o quadro político quando se está "preso" à linha de montagem: "E cinquenta horas por semana de trabalho na linha de montagem de motores numa fábrica de tratores ou de automóveis, são elas mais "atraentes" em Gorki do que em Detroit ?" (Rot \& Vatin, 2004: nota 69, tradução livre).

Podemos constatar um processo de evolução análogo, em ergonomia, com A. Wisner. Com efeito, este começará por realizar pesquisas experimentais, mas sem nunca se comprometer na utilização dos seus resultados, tendo depois adoptado uma nova postura implicando o estudo direto no terreno. Mesmo se tal perspetiva era então considerada pelo meio científico como "literatura", não digna, pois, de publicação nas revistas científicas. Porém, A. Wisner descobre que os "dois primeiros estudos realizados com os sindicalistas colocaram ao nosso laboratório questões totalmente novas: metodologias, ciências necessárias ao nosso progresso e relações com a vida social. Trata-se de uma verdadeira reviravolta!". Mas "ir para o terreno não significa renunciar a estabelecer factos científicos novos. Para retomar as palavras do psicólogo inglês Tom Singleton: "Eu preocupo-me com psicologia fundamental, por isso é que vou aos locais de trabalho" (Wisner, 1985, p. 30, tradução livre).

Esta será a minha palavra final!

\section{BIBLIOGRAFIA}

AEP- Agence Européenne de Productivité (1959). Adaptation du travail à l'Homme. Recherches américaines et européennes sur les conditions de travail dans l'industrie. Paris : OECE (Organisation Européenne de Coopération Economique) éd.

Alaluf, M. (2001). L'analyse du travail et son organisation. Formation et Emploi, 76, 99-103.

Alaluf, M. (2012). Sociologie, in A. Bevort, A. Jobert, M. Lallemand \& A. Mias (coord.) Dictionnaire du travail (pp. 727-733). Paris : PUF. 
Brucy, G. (2001). La doctrine de la CGT sur la formation des adultes : entre pragmatisme et lutte de classes (1945-1955). Travail et Emploi, 86, 65-85.

Crozier, M. (1956). Petits fonctionnaires au travail. Paris : Editions du CNRS.

Crozier, M. (2002). Ma belle époque : mémoires [1], 1947-1969. Paris : Fayard.

David, M. (1982). Témoins de l'impossible. Militants du monde ouvrier à l'université. Paris : Editions ouvrières.

Despret, V. (2011). Que diraient les animaux, si ... on leur posait les bonnes questions ? Paris : Les empêcheurs de tourner en rond / La Découverte (rééd. 2014 La Découverte / Poche).

Faverge, J.M., Browaeys, R., \& Leplat, J. (1956). Enquête sur les programmes de formation existant au sein des entreprises. Bulletin du CERP (Centre d'Etudes et de Recherches Psychotechniques), 6, 3, 235-324.

Febvre, L. (1951). Travail, travailleurs (revue bibliographique). Annales, 6, 2, 241-242.

Friedmann, G. (1934). Problèmes du machinisme en URSS et dans les pays capitalistes, Paris : Editions Sociales internationales.

Friedmann, G. (1941/1948). Esquisse d'une psycho-sociologie du travail à la chaîne, in Ignace Meyerson et al. (1948) Le travail et les techniques (pp. 127-144). Paris : PUF.

Friedmann, G. (1946). Problèmes humains du machinisme industriel. Paris : Gallimard.

Friedmann, G. (1950). Où va le travail humain? Paris : Gallimard.

Friedmann, G. (1954). Intervention au XIème Congrès International de Psychotechnique

(Psychologie appliquée), Section de psychologie du travail, Paris, 1953. Le Travail Humain, 17, 1-2, 39-40.

Friedmann, G. (1962). La grande aventure. Arguments, $\mathrm{n}^{\circ}$ 27-28.

Friedmann, G., \& Naville, P. (coord.) (1962). Traité de sociologie du travail. Paris : A. Colin.

Friedmann, G., \& Reynaud, J.-D. (1958). Sociologie des techniques de production et du travail, in G. Gurvitch (coord.) Traité de sociologie, t. 1 (pp. 443-460), Paris : PUF.

Frisby, C. B. (1954). Allocution inaugurale. Le Travail Humain, XVII, 1-2.

Glaser, B.G., \& Strauss, A.L. (1967). The Discovery of Grounded Theory; Stratégies for Qualitative Research. Chicago : Aldine de Gruyter.

Godelier, M. (2000). Le métier de chercheur. Sciences de l'Homme et de la Société - CNRS, 58, 12-18.

Goguelin, P. (1954). Les facteurs psychologiques susceptibles d'accroître la productivité dans l'entreprise. Le Travail Humain, t. XVII, nº 1-2, 12-33.

Hearnshaw, L. S. (1954). Le but et le domaine de la Psychologie industrielle. Le Travail Humain, XVII ${ }^{\circ}$ année, 1-2, 4-11.

Heilbron, J. (1991). Pionniers par défaut. Revue Française de Sociologie, XXXII/3, 365-379.

Isambert-Jamati, V. (1955). L'industrie horlogère dans la région de Besançon. Paris : PUF.

Kuisel, R. F. (1988). L'American way of life et les missions françaises de productivité. Vingtième Siècle. Revue d'histoire, 17, 17, 21-38.

Kuty, O. (2008). La naissance de la négociation (1933-1962). Sociologies [Online], Theory and research, Online since 28 October 2008, URL : http://sociologies.revues.org/2483 
Lacomblez, M., Teiger, C., \& Vasconcelos, R. (2014). A ergonomia e o "paradigma da formação dos atores": uma parceria formadora com os protagonistas do trabalho, in F. P. Bendassolli \& L. A. Soboll (Org.), Métodos de pesquisa e intervenção em psicologia do trabalho: clínicas do trabalho (pp. 159-183; capítulo 7). São Paulo : Ed. Atlas.

Lahy, J.-M. (1932). Les fondements scientifiques de la psychotechnique. Communication à la VII ${ }^{\mathrm{e}}$ Conférence de psychotechnique, Moscou (1931), in Gouarné, I. (2007). Les conditions d'émergence du philosoviétisme dans l'univers de la psychologie scientifique française de l'entre-deuxguerres. Cahiers d'histoire. Revue d'histoire critique, 102 | 2007 : Sciences et politique. DOSSIER : La VIIe Conférence de psychotechnique (Moscou, septembre 1931), 65-87.

Muniz, H., Brito, J., Souza, K. R., Athayde, M., \& Lacomblez, M. (2013). Ivar Oddone e sua contribuição para o campo da Saúde do Trabalhador no Brasil. Revista Brasileira de Saúde Ocupacional, 38, 280-291.

Oddone, I., Re, A., \& Briante, G. (1977). Esperienza operaia, coscienza di classe e psicologia del lavoro, Turín: Einaudi. (Trad. francesa, 1981: Redécouvrir l'expérience ouvrière. Vers une autre psychologie du travail, París: Éditions sociales).

Ombredane, A., \& Faverge, J.-M. (1955). L'analyse du travail. Facteur d'économie humaine et de productivité. Paris : PUF.

ROT, G., \& VATIN, F. (2004). Les avatars du « travail à la CHAÎNE » dans l'œuvre de Georges Friedmann (1931-1966). Genèses 4/2004, 57, 23-40. URL: www.cairn.info/revue-geneses-2004-4page-23.htm.

Rot, G., \& Vatin, F. (2008). L'enquête des « Gaston » ou les sociologues au travail. Jacques Dofny et Bernard Mottez à la tôlerie du Mont-Saint-Martin en 1955. Actes de la recherche en sciences sociales, 5 (175), 62-81.

Russell, S. (2015). Non aux robots de combat., le Monde, 8 août 2015, p. 14.

Teiger, C. (2007). De l'irruption de l'intervention dans la recherche en ergonomie. Education permanente, 170/2007-1, 35-49 (dossier Intervention et savoirs).

Teiger, C. (2015a). Jean-Marie Faverge en Amérique (1952) - Préludes à L'analyse du travail (1955). In R. Ouvrier-Bonnaz \& A. Weill-Fassina (coord.) L'analyse du travail, ruptures et évolutions. Toulouse : Octarès éd. (Téléchargement gratuit sur www.octares.com).

Teiger, C. (2015b). Laboratório. “Onde fazer ciência”?. Laboreal, 11 (1), 121-126. http://dx.doi.org/ 10.15667/laborealxi0115ct

Teiger, C., \& Lacomblez, M. (coord.) (2013). (Se) former pour transformer le travail - Dynamiques de constructions d'une analyse critique du travail. Québec (Canada-Qc,) PUL-Presses de l'Université Laval et Bruxelles : ETUI-European Trade Union Institut éds.

Teiger, C., \& Leal Ferreira L. (2015). Escrever juntos um livro (ergonomistas e sindicalistas): uma ferramenta para a dinamîca pesquisa - formaçâo - açâo. In F. M. G. Vezzá, A. M. Iguti, M. A. Bussacos, M. C. Gonzaga, \& S. Donatelli (org.), Análises do trabalho: escritos escolhidos / Leda Leal Ferreira (pp.51-62). Belo Horizonte, Fabrefactum Ed. Ltda.

Touraine, A. (1955). L'évolution du travail ouvrier aux usines Renault. Paris : Presses du CNRS.

Tournès, L. (2008). La fondation Rockefeller et la construction d'une politique des sciences sociales en France (1918-1940). Annales. Histoire, Sciences Sociales, EHESS, 63 (6), 1371-1402. (halshs-00652586) 
Varro, G., \& Perriaux A.S. (1991). Les sens d'une catégorisation : « Les O.S. immigrés ». Langage et société, 58, 5-36.

Verey, É., \& Touraine, A. (1949). Enquête française de sociologie industrielle. Cahiers internationaux de sociologie, 7, 118-119.

Verry, M. (1955). Les Laminoirs ardennais. Déclin d'une aristocratie professionnelle. Paris : PUF.

Westerlund, G. (1954). Cadre de références et problèmes liés en psychologie industrielle. Le Travail Humain, $\mathrm{XVII}^{\circ}$ année, 34-38.

Wisner, A. (1985). Quand voyagent les usines. Essai d'anthropologie. Paris : Syros.

\section{NOTAS}

1. Os dois termos parecem ser empregues indiferenciadamente na época, estando a psicologia do trabalho arrumada na psicologia aplicada / psicotécnica.

2. Diretor do National Institute of Industrial Psychology, Londres, presidente da secção.

3. Professor de Psicologia na Universidade de Liverpool.

4. Professor de Psicologia do trabalho no Conservatoire National des Arts et Métiers (CNAM), Paris (de 1970 a 1989)

5. Professor de Psicologia social na Stockholm School of Economics.

6. Nascido em 1872, e falecido em 1943, investigador engajado e profissional da psicotécnica, J.-M. Lahy funda em 1924 o primeiro laboratório psicotécnico na S.T.C.R.P. ("Société de transport en commun de la région parisienne") e, em 1931, o "Service psychotechnique des chemins de fer du Nord". Diretor do "Laboratoire de psychologie appliquée" de l' "École pratique des hautes études" em 1927, o seu primeiro mestre, Edouard Toulouse, apresentou-o como "o maior obreiro da psicotécnica científica”. É cofundador da revista Le travail humain em 1933.

7. $O$ artigo de P. Goguelin (1954) relata precisamente um inquérito aos participantes de 128 destas missões (de aproximandamente 500) com vista a definir o papel e a formação adequada do psicólogo industrial numa perspetiva de produtividade.

8. Inspirei-me largamente em Mateo Alaluf (2012), Olgierd Kuty (2008), Gwenaëlle Rot e François Vatin (2004).

9. 0 "Centro de Documentação Social" (centro financiado pelo banqueiro e mecenas Albert Kahn e igualmente beneficiário dos fundos americanos da Fundação Rockefeller), foi fundado em 1920 por Célestin Bouglé (1870-1940), filósofo e sociólogo, professor na Sorbonne, em Paris, diretor da École Normale Supérieure a partir de 1935.

10. Entre os autores das Atas, figuram I. Meyerson, fundador da psicologia histórica, que no prefácio define o trabalho como uma conduta, o antropólogo Marcel Mauss ("Les techniques et la technologie; plaidoyer pour cette dernière et essais de définitions" - "As técnicas e a tecnologia; defesa desta última e tentativas de definição"), o historiador Marc Bloch, ("Les transformations des techniques comme problème de psychologie collective" - "As transformações das técnicas como problema da psicologia coletiva"). A contribuição de L. Febvre ("Travail : évolution d'un mot et d'une idée" - "Trabalho: evolução de uma palavra e de uma ideia") é apresentada por Fernand Braudel, historiador, na mesma rubrica dos Annales (1951, p. 243).

11. M. Alaluf (2012: 729) assinala que L'analyse du travail. Facteur d'économie humaine et de productivité de Ombredane \& Faverge (1955) é a obra mais citada neste tratado de sociologia do trabalho.

12. Parece contudo que a entrevista não ocupou um lugar de destaque (Crozier, 2002).

13. Cf. os trabalhos inovadores da altura do Centre de Documentation Sociale da ENS com o apoio dos fundos americanos da Fundação Rockefeller (Tournès, 2008). 
14. Alto funcionário do Ministério do trabalho, professor de Direito social no CNAM (de 1976 a 1991).

15. Professor de História do direito na Universidade de Estrasburgo.

16. Professor de História do direito na Universidade de Estrasburgo.

17. Trata-se de Jacques Dofny, Bernard Mottez e Adrien Morel e depois Claude Durand, Paul Pascon e Philippe Pigenet (Rot \& Vatin, 2008).

18. Trata-se de Jacques Dofny, Bernard Mottez e Adrien Morel e depois Claude Durand, Paul Pascon e Philippe Pigenet (Rot \& Vatin, 2008).

19. Ex-diretor do departamento de ciências humanas e sociais do CNRS.

20. Recordemos que em França, até à sua autonomização académica, da psicologia em 1947 e da sociologia em 1958, estas duas disciplinas faziam parte do ensino da filosofia.

21. Período que, em sociologia, corresponde à defesa da abordagem indutiva e qualitativa por Glaser \& Strauss (1967) conducente a uma "teoria ancorada nos factos".

22. Ver os exemplos em "Laboratório" (Teiger, 2015b) no Dicionário da Laboreal.

23. Cf. o artigo de Stuart Russell, no Le Monde de 8 de agosto de 2015, p. 14: "Non aux robots de combat" ("Não aos robots de combate") que faz alusão às reações "irresponsáveis" de alguns cientistas face às investigações que conduziram à produção da bomba atómica.

24. Em 1949, em França, G. Friedmann pôde apoiar-se na pesquisa de E. Verley e A. Touraine (1949) nas fábricas Renault, à qual faz referência na edição de 1950 da sua obra Où va le travail humain? (Friedmann, 1950).

\section{AUTOR}

\section{CATHERINE TEIGER}

Groupe de recherche sur l'histoire du travail et de l'orientation (GRESHTO), Centre de recherche sur le travail et le développement (CRTD), Conservatoire National des Arts et Métiers, 41 rue GayLussac, 70005 Paris, France

moufcat@gmail.com 